\title{
Appraising healthcare systems' efficiency in facing COVID-19 through data envelopment analysis
}

\author{
Nahia Mourad ${ }^{a *}$, Ahmed Mohamed Habib ${ }^{b}$ and Assem Tharwat ${ }^{a}$
}

\begin{abstract}
${ }^{a}$ American University in the Emirates, Dubai, United Arab Emirates
${ }^{b}$ Zagazig University, Zagazig, Egypt

C H R O N I C L E Article history:

Received December 28, 2020

Received in revised format:

January 30, 2021

Accepted March 92021

Available online

March 9, 2021

Keywords:

Healthcare systems

Covid-19 pandemic

Data envelopment analysis (DEA)

Technical efficiency

Decision-making units (DMUs)

Mathematical programming

A B S T R A C T

The healthcare system is a vital element for any community, as it extremely affects the socioeconomic development of any country. The current study aims to assess the performance of the healthcare systems of the countries above fifty million citizens in facing the spread of the COVID-19 pandemic since late December 2019. For this purpose, seven scenarios were adopted via the DEA methodology with six variables, which are the number of medical practitioners (doctors and nurses), hospital beds, Conducted Covid-19 tests, affected cases, recovered cases, and death cases. To shed light on the relative efficiency of drivers, the Tobit analysis was used. Besides, the study carried out various statistical tests for the DEA models' findings to validate the choice of the variables and the obtained scores. The DEA results reveal that less than half of the considered countries are relatively efficient. Moreover, the Tobit regression analysis showed that the main impact on the efficiency scores was due to the number of affected and recovered cases. Finally, the results of the tests of Spearman, Mann-Whitney U, and Kruskal-Wallis H indicate the internal validity and robustness of the chosen DEA models. The current study findings raise important implications, which can be helpful for decision makers regarding continuous improvement of performance, in which the findings assert the importance of achieving the best practices regarding relative efficiency through the linkage between the healthcare systems' resources, and the needed outputs.
\end{abstract}

\section{Introduction}

Covid-19 is an infectious disease, which initially appeared in Wuhan, in December 2019. This disease is a cause of novel coronavirus, which influences the respiratory system. It caused the outbreak of a Worldwide pandemic due to its fast spread and the unavailability of vaccines or specific treatment. More than forty million confirmed affected cases, and one million deaths by Covid-19 worldwide, at the end of September 2020. These numbers are severely affected by the healthcare systems' circumstances of each country.

Indeed, the healthcare systems' efficiency improvement has been one of the main concerns of all developed countries. It is worth studying the performance of these systems in facing Covid-19. DEA (Charnes et al., 1978) is an efficiency measurement method, which is incorporated in many applications, among these is comparing the healthcare systems' performance of different countries (e.g. Alexander et al., 2003; Kohl et al., 2019; Ibrahim et al., 2019; Masiye, 2007; Unger \& De Paepe, 2019). Zakowska and Godycki-Cwirko (2020) did a systematic review of the application of DEA in the evaluation of primary healthcare, in pursuit of standardization of this method. As pointed, the metrics and models used are not conventional, therefore, further research is required.

In the current paper, the healthcare systems' relative efficiency in highly populated countries is evaluated. The DEA method, with output and input orientation, is used for this purpose. Indeed, the DEA models in the current study adopt four inputs

* Corresponding author.

E-mail address: nahia.mourad@aue.ae (N. Mourad)

(C) 2021 by the authors; licensee Growing Science, Canada.

doi: $10.5267 /$ j.dsl.2021.2.007 
and two outputs. The input variables of the adopted DEA models involve the number of affected cases, medical practitioners, hospital beds, and total conducted Covid-19 tests, (all numbers are per million), whereas the output variables are the number of recovered and death cases per million. Moreover, the Tobit regression analysis is used to check the relation between the DEA efficiency scores and the chosen variables, in addition to checking the dependency of these scores on the GDP per Capita. Lastly, a robustness test is applied to verify the correctness of the findings. The used statistical tests to support the results are the Sign, Wilcoxon, Mann-Whitney U, Kruskal-Wallis H, and Spearman rank. In brief, the following research questions will be resolved in the current study:

RQ1. Is there relative efficiency in the healthcare systems' performance in the highly populated countries facing Covid-19 over the study period?

RQ2. Is there a significant variance between the healthcare systems' efficiency scores via the output-orientation model and the input-oriented model over the study period?

RQ3. Do the variables under analyses have no significant influence on the healthcare systems' efficiency scores over the study period?

RQ4. Does the GDP per capita have no significant influence on the efficiency scores of the healthcare systems over the study period?

The exposition of the paper is as follows. In Section 2 a detailed explanation of the used methodology is presented. The used DEA models are identified, together with the Tobit regression model, besides, a concise explanation for the used statistical tests is pointed out. Following, in Section 3 the obtained efficiency scores resulting from the DEA are analyzed. Then, in Section 4 Tobit regression and robustness tests are presented and discussed to support the DEA results. Section 5 concludes the work done.

\section{Methodology}

The main work in this study consists of data collection, selecting the inputs and outputs, implementing the DEA technique to evaluate the healthcare systems' efficiency of highly populated countries (DMUs) facing Covid-19, and finally developing Tobit regression to point out the determinants of the efficiency of the selected sample. We pinpointed 29 healthcare systems of highly populated countries facing Covid-19 based on data obtained through the World Healthcare Organization and Worldometers homepages throughout Jan-Sep 2020, the sample size within the current study is appropriate for applying the DEA technique according to the used variables, as Golany and Roll (1989) recommended that the number of DMUs should be greater than twice the number of inputs and outputs within the DEA model, whereas Banker et al. (1989) and Cooper et al. (2007) suggested that the number of DMUs should be greater than three times the number of inputs and outputs within the DEA model, for the results to be reasonable and acceptable. In subsequent, the used models in this study are displayed together with their purpose (Koltai \& Uzonyi-Kecskes, 2017; Lo Storto, 2013; Tone, 2016).

\subsection{DEA model}

DEA is a mathematical programming approach that can provide helpful information to assess and optimize the relative efficiency of comparable DMUs (Emrouznjad \& Yang, 2008). It is a nonparametric approach, where no assumptions on the population data are restricting its usage. The well-known efficiency score for peer objects, which are the DMUs, is the quotient of the weighted output to the weighted input. The introduced weights allow the possibility of considering multiple variables that are not necessarily of the same type. This strengthens the DEA method. For $N$ comparable DMUs, let $\left\{x_{i n}\right\}_{1 \leq i \leq m}$ represent the inputs for the $n$-th DMU, and $\left\{y_{j n}\right\}_{1 \leq j \leq s}$ represent its outputs. The score of efficiency can be calculated by disbanding the following formula:

$$
e_{n}=\max _{(\mu, v) \in R_{+}^{m \times s}} \frac{\sum_{j=1}^{s} v_{j} y_{j n}}{\sum_{i=1}^{m} \mu_{i} x_{i n}}, \quad \text { where } \frac{\sum_{j=1}^{s} v_{j} y_{j n}}{\sum_{i=1}^{m} \mu_{i} x_{i n}} \leq 1 \text { for } n=1, \ldots, N
$$

where $\mu$ and $v$ are the vectors of the weights associated with the inputs and outputs. This fractional problem can be simply transformed into a linear one. However, one has to choose the orientation in advance. There are two available orientations, either output or input-oriented model. The choice of the model orientations depends on the variables under investigation. The first is chosen in case the decision-makers have control over decreasing the inputs, whereas the output orientation is chosen in case they have control over increasing the outputs while retaining the same input level. The two linear problems, which are known by multiplier forms, are:

Input-Oriented:

$$
\max _{(\mu, v) \in \mathbb{R}_{+}^{m \times s}} \sum_{j=1}^{s} v_{j} y_{j n}
$$

and
Output-Oriented

$$
\min _{(\mu, v) \in R_{+}^{m \times s}} \sum_{i=1}^{m} \mu_{i} x_{i n}
$$




$$
\begin{array}{cc}
\sum_{i=1}^{m} \mu_{i} x_{i n}=1 & \sum_{j=1}^{s} v_{j} y_{j n}=1 \\
\sum_{j=1}^{s} v_{j} y_{j n}-\sum_{i=1}^{m} \mu_{i} x_{i n} \leq 0 & \sum_{j=1}^{s} v_{j} y_{j n}-\sum_{i=1}^{m} \mu_{i} x_{i n} \leq 0
\end{array}
$$

In practice, following the fact that the number of DMUs $(N)$ is much more than the number of the considered variables $(m+s)$, the dual of these problems are considered, so that fewer number of constraints are obtained (Banker et al., 1984). The accompanying duals, which are known by envelopment forms, are:

$$
\begin{array}{cc}
\begin{array}{c}
\text { Input-oriented } \\
e_{n}=\min _{\lambda \in \mathbb{R}_{+}^{N}}\left(\theta_{n}\right)
\end{array} & \begin{array}{c}
\text { Output-oriented } \\
\frac{1}{e_{n}}=\max _{\lambda \in \mathbb{R}_{+}^{N}}\left(\theta_{n}\right) \\
\sum_{j=1}^{N} \lambda_{j} x_{i j} \leq \theta_{n} x_{i n}, \quad i=1, \ldots, m
\end{array} \quad \text { and } \quad \sum_{j=1}^{N} \lambda_{j} x_{i j} \leq x_{i n}, \quad i=1, \ldots, m \\
\sum_{j=1}^{N} \lambda_{j} y_{r j} \geq y_{r n}, \quad r=1, \ldots, s & \sum_{j=1}^{N} \lambda_{j} y_{r j} \geq \theta_{n} y_{r n}, \quad r=1, \ldots, s
\end{array}
$$

where $\lambda$ is the vector of the weights associated with the DMUs. In 1984, Banker et al. added one constraint on the weight vector to be unit in $L^{1}(\mathbb{R})$. That is:

$$
\sum_{j=1}^{N} \lambda_{j}=1
$$

This last constraint removes the assumption that a variation in either inputs or outputs leads to a proportional variation in the other. It's worth noting that the optimization problem should be solved for each DMU. If the efficiency score obtained by solving one of the above problems is equal to one, then the DMU is considered relatively efficient, otherwise, it's not efficient. Further, these models were enhanced to handle uncertain variables like stochastic (Olesen and Petersen, 2016; Mourad and Tharwat, 2019), fuzzy (Hatami-Marbini et al. 2011), and roughness variables (Chen et al., 2020).

\subsection{Tobit model}

Regarding verifying the drivers of efficiency scores of the selected sample. The current study adopted the Tobit regression analysis to verify the key factors that influence the healthcare systems' efficiency scores. The Tobit analysis is a powerful tool for verifying the impact of the efficiency scores' drivers under investigation (Habib \& Shahwan, 2020; Wang et al. 2016; Zheng et al, 2018). Mathematically, this Tobit model belongs to the family of regression models, which was proposed by James Tobin in 1958. Tobit analysis is the best regression model to be used when the dependent variable has a range constraint (Verbeek 2008). To build the Tobit model, for $n$ data point, non-observed dependent variables $y_{i}^{*}$, known also as latent variables, are created by

$$
y_{i}^{*}=X_{i}^{T} \beta+\epsilon_{i}, \quad i=1,2, \ldots, n
$$

where $\epsilon_{i}$ are Gaussian noises, which are random errors, and $X_{i}$ are vectors containing the data corresponding to the independent variables. The regression is done for the non-observed data points and the observed dependent variables are then given by:

$$
y_{i}=\max \left(y_{i}^{*}, 0\right), \quad i=1,2, \ldots, n
$$

For $m$ independent variables, the linear multivariate regression relation can be expressed as follows:

$$
y=X^{T} \beta=\beta_{0}+\beta_{1} x_{1}+\cdots+\beta_{m} x_{m}
$$

where $\theta=\left(\beta_{0}, \beta_{1}, \ldots, \beta_{m}, \sigma\right)$ maximizes what's known by the log-likelihood function, which is given by

$$
L_{n(\theta)}=\frac{1}{n} \sum_{i=1}^{n}\left(1-\delta_{y_{i}=0}\right) \log \left[\frac{1}{\sigma} \phi\left(\frac{y_{i}-X_{i}^{T} \beta}{\sigma}\right)\right]+\delta_{y_{i}=0} \log \left[\Phi\left(\frac{y_{i}-X_{i}^{T} \beta}{\sigma}\right)\right] .
$$




\subsection{Statistical tests}

We end this section by giving the role of the tests utilized in the current study. It should be noted that all the utilized tests are non-parametric. First, the Sign test examines the significant difference of the median between two sets based on the binomial distribution. Second, the Wilcoxon test compares paired groups based on Wilcoxon distribution, under the assumption that the data come from the same population. Third, the Mann-Whitney $\mathrm{U}$ test is the same as the previous one, however, it assumes that the population of the two samples are independent, its test statistic is the U-distribution. Fourth, the Kruskal-Wallis $\mathrm{H}$ test identifies whether the medians of two or more groups are significantly different, it's an alternative of the one-way ANOVA; its test statistic is the H-distribution, and it's considered as an extension of the Mann-Whitney U test. Fifth and last, the Spearman rank test studies the correlation between two groups depending on the rank of the data points.

\section{DEA Analysis}

In this section, the DEA results for measuring the performance of the healthcare systems in the 29 countries, with a population of more than 50 million, are stated and analyzed. Moreover, the following two assumptions are tested:

A1. At least 50\% of the healthcare systems in the investigated countries are inefficient in facing Covid-19, based on the DEA models.

A2. Not all the considered input and output variables have a significant influence on the healthcare systems' efficiency scores.

The study adopted multi scenarios that are considered to indicate the influence of the variables under study on the performance of the healthcare systems and to identify the cause(s) of inefficiency for each DMU if needed. These scenarios are as follows:

- Scenario 1. The input variables are the number of affected cases, medical practitioners, hospital beds, and conducted tests, whereas the output variables are the number of recovered and death cases.

- Scenario 2. The number of death cases is removed from the variables taken in the $1^{\text {st }}$ Scenario.

- Scenario 3. The number of conducted Covid-19 tests is removed from the variables taken in the $1^{\text {st }}$ Scenario.

- Scenario 4. The number of conducted Covid-19 tests and death cases are both removed from the variables taken in the $1^{\text {st }}$ Scenario.

- Scenario 5. The number of affected cases, as input, and recovered cases, as output, are the only variables included via the DEA model.

- Scenario 6. The number of medical practitioners is added to the variables taken in the $5^{\text {th }}$ Scenario.

- Scenario 7. The number of hospital beds is added to the variables taken in the $5^{\text {th }}$ Scenario.

Table 1 summarizes the descriptive statistics of the collected data set from WHO, Worldometers, Coronatracker, Index Mundi, and International Monetary Fund websites. It shows the minimum, maximum, mean, and standard deviation.

Table 1

Descriptive statistics summary of the data set

\begin{tabular}{lcccc}
\multicolumn{1}{c}{ Variables } & Min. & Max. & Mean & Std. Dev. \\
\hline Total Cases (per million) & 8 & 22606 & 4688 & 6297.3 \\
Total medical practitioners (per million) & 590 & 17490 & 5847.6 & 5401.2 \\
Total beds (per million) & 300 & 13050 & 2999 & 3349.8 \\
Total recovered (per million) & 3 & 19632 & 3466.8 & 5009.4 \\
1/ Total deaths (per million) & .001 & 3.333 & .29964 & .771185 \\
Total Tests (per million) & 609 & 360527 & 79589.8 & 104034.9 \\
GDP (per capita \$) & 500.6 & 65111.6 & 12814.1 & 17479.6 \\
\hline
\end{tabular}

The data set refer that the average of total cases per million was about 4688 in a range of 8 to 22606 with a standard deviation of 6297, the average of total medical practitioners per million was about 5848 in a range of 590 to 17490 with a standard deviation of 5401, the average of total beds (per million) was about 2999 in a range of 300 to 13050 with a standard deviation of 3350, the average of total recovered (per million) was about 3467 in a range of 3 to 19632 with a standard deviation of 5009 , the average of the reverse ratio of total death cases (per million) was about .29964 in a range of .001 to 3.33 with a standard deviation of .7712, the total tests per million average was about 79590 in a range of 609 to 360527 with a standard deviation of 104035, and the total GDP per capita average was about 12814 in a range of 501 to 65112 with a standard deviation of 17480. In Table 2, the output/input-oriented scenarios are discussed to support the decision-makers from two perspectives: either planning to increase the recovered cases under the available resources or optimize the utilization of the current resources by reducing the expenses considering the current recovery rates. Panel A, based on the DEA output- 
oriented model for all Scenarios, reveals the relative technical efficiency results for 29 healthcare systems of the highly populated countries facing Covid-19 over the period (Jan-Sep 2020).

Table 2

The relative efficiency scores summary

Panel A: Relative efficiency summary via DEA-output-orientation

\begin{tabular}{|c|c|c|c|c|c|c|c|}
\hline \multirow{2}{*}{ DMUs (ISO Code) } & \multicolumn{7}{|c|}{ Relative efficiency scores } \\
\hline & Scenario 1 & Scenario. 2 & Scenario 3 & Scenario 4 & Scenario 5 & Scenario 6 & Scenario 7 \\
\hline $\mathrm{CHN}$ & 1.000 & 1.000 & 1.000 & 1.000 & 1.000 & 1.000 & 1.000 \\
\hline IND & 1.000 & 1.000 & 1.000 & 1.000 & 0.916 & 0.916 & 1.000 \\
\hline USA & 0.726 & 0.726 & 0.726 & 0.726 & 0.726 & 0.726 & 0.726 \\
\hline IDN & 0.787 & 0.787 & 0.787 & 0.787 & 0.787 & 0.787 & 0.787 \\
\hline PAK & 1.000 & 1.000 & 1.000 & 1.000 & 1.000 & 1.000 & 1.000 \\
\hline BRA & 1.000 & 1.000 & 1.000 & 1.000 & 1.000 & 1.000 & 1.000 \\
\hline NGA & 1.000 & 1.000 & 1.000 & 1.000 & 0.900 & 0.900 & 1.000 \\
\hline BGD & 0.916 & 0.916 & 0.860 & 0.860 & 0.814 & 0.839 & 0.814 \\
\hline RUS & 0.901 & 0.901 & 0.901 & 0.901 & 0.901 & 0.901 & 0.901 \\
\hline MEX & 1.000 & 1.000 & 0.792 & 0.792 & 0.792 & 0.792 & 0.792 \\
\hline JPN & 0.964 & 0.964 & 0.964 & 0.964 & 0.964 & 0.964 & 0.964 \\
\hline ETH & 1.000 & 1.000 & 1.000 & 1.000 & 0.436 & 0.455 & 1.000 \\
\hline PHL & 0.881 & 0.881 & 0.881 & 0.881 & 0.881 & 0.881 & 0.881 \\
\hline EGY & 1.000 & 1.000 & 0.984 & 0.984 & 0.984 & 0.984 & 0.984 \\
\hline VNM & 1.000 & 1.000 & 1.000 & 1.000 & 1.000 & 1.000 & 1.000 \\
\hline DRC & 1.000 & 1.000 & 1.000 & 1.000 & 0.999 & 1.000 & 1.000 \\
\hline TUR & 0.959 & 0.959 & 0.959 & 0.959 & 0.959 & 0.959 & 0.959 \\
\hline IRN & 0.916 & 0.916 & 0.916 & 0.916 & 0.916 & 0.916 & 0.916 \\
\hline DEU & 0.953 & 0.953 & 0.953 & 0.953 & 0.953 & 0.953 & 0.953 \\
\hline THA & 0.997 & 0.997 & 0.997 & 0.997 & 0.993 & 0.994 & 0.997 \\
\hline GBR & 0.329 & 0.329 & 0.329 & 0.329 & 0.329 & 0.329 & 0.329 \\
\hline FRA & 0.190 & 0.190 & 0.190 & 0.190 & 0.190 & 0.190 & 0.190 \\
\hline ITA & 0.795 & 0.795 & 0.795 & 0.795 & 0.795 & 0.795 & 0.795 \\
\hline TZA & 1.000 & 1.000 & 1.000 & 1.000 & 1.000 & 1.000 & 1.000 \\
\hline ZAF & 1.000 & 1.000 & 1.000 & 1.000 & 1.000 & 1.000 & 1.000 \\
\hline MMR & 0.297 & 0.296 & 0.297 & 0.296 & 0.296 & 0.296 & 0.296 \\
\hline KEN & 0.681 & 0.681 & 0.681 & 0.681 & 0.680 & 0.681 & 0.680 \\
\hline KOR & 0.954 & 0.954 & 0.954 & 0.954 & 0.954 & 0.954 & 0.954 \\
\hline $\mathrm{COL}$ & 1.000 & 1.000 & 1.000 & 1.000 & 1.000 & 1.000 & 1.000 \\
\hline Mean & 0.871 & 0.87 & 0.861 & 0.861 & 0.833 & 0.835 & 0.859 \\
\hline \multicolumn{8}{|c|}{ Panel B: Relative efficiency summary via DEA-input-oriented } \\
\hline \multirow{2}{*}{ DMUs (ISO Code) } & \multicolumn{7}{|c|}{ Relative efficiency scores } \\
\hline & Scenario 1 & Scenario 2 & Scenario 3 & Scenario 4 & Scenario 5 & Scenario 6 & Scenario 7 \\
\hline $\mathrm{CHN}$ & 1.000 & 1.000 & 1.000 & 1.000 & 1.000 & 1.000 & 1.000 \\
\hline IND & 1.000 & 1.000 & 1.000 & 1.000 & 0.914 & 0.914 & 1.000 \\
\hline USA & 0.704 & 0.704 & 0.704 & 0.704 & 0.704 & 0.704 & 0.704 \\
\hline IDN & 0.788 & 0.788 & 0.788 & 0.788 & 0.787 & 0.787 & 0.788 \\
\hline PAK & 1.000 & 1.000 & 1.000 & 1.000 & 1.000 & 1.000 & 1.000 \\
\hline BRA & 1.000 & 1.000 & 1.000 & 1.000 & 1.000 & 1.000 & 1.000 \\
\hline NGA & 1.000 & 1.000 & 1.000 & 1.000 & 0.900 & 0.900 & 1.000 \\
\hline BGD & 0.966 & 0.966 & 0.941 & 0.941 & 0.807 & 0.864 & 0.807 \\
\hline RUS & 0.900 & 0.900 & 0.900 & 0.900 & 0.900 & 0.900 & 0.900 \\
\hline MEX & 1.000 & 1.000 & 0.789 & 0.789 & 0.788 & 0.788 & 0.789 \\
\hline JPN & 0.964 & 0.964 & 0.964 & 0.964 & 0.964 & 0.964 & 0.964 \\
\hline ETH & 1.000 & 1.000 & 1.000 & 1.000 & 0.436 & 0.801 & 1.000 \\
\hline PHL & 0.878 & 0.878 & 0.878 & 0.878 & 0.878 & 0.878 & 0.878 \\
\hline EGY & 1.000 & 1.000 & 0.984 & 0.984 & 0.984 & 0.984 & 0.984 \\
\hline VNM & 1.000 & 1.000 & 1.000 & 1.000 & 1.000 & 1.000 & 1.000 \\
\hline DRC & 1.000 & 1.000 & 1.000 & 1.000 & 0.999 & 1.000 & 1.000 \\
\hline TUR & 0.958 & 0.958 & 0.958 & 0.958 & 0.958 & 0.958 & 0.958 \\
\hline IRN & 0.915 & 0.915 & 0.915 & 0.915 & 0.915 & 0.915 & 0.915 \\
\hline DEU & 0.952 & 0.952 & 0.952 & 0.952 & 0.952 & 0.952 & 0.952 \\
\hline THA & 0.997 & 0.997 & 0.997 & 0.997 & 0.993 & 0.994 & 0.997 \\
\hline GBR & 0.320 & 0.320 & 0.320 & 0.320 & 0.320 & 0.320 & 0.320 \\
\hline FRA & 0.182 & 0.182 & 0.182 & 0.182 & 0.182 & 0.182 & 0.182 \\
\hline ITA & 0.791 & 0.791 & 0.791 & 0.791 & 0.791 & 0.791 & 0.791 \\
\hline TZA & 1.000 & 1.000 & 1.000 & 1.000 & 1.000 & 1.000 & 1.000 \\
\hline $\mathrm{ZAF}$ & 1.000 & 1.000 & 1.000 & 1.000 & 1.000 & 1.000 & 1.000 \\
\hline MMR & 0.656 & 0.656 & 0.656 & 0.656 & 0.297 & 0.357 & 0.655 \\
\hline KEN & 0.690 & 0.690 & 0.689 & 0.689 & 0.680 & 0.689 & 0.680 \\
\hline KOR & 0.954 & 0.954 & 0.954 & 0.954 & 0.954 & 0.954 & 0.954 \\
\hline $\mathrm{COL}$ & 1.000 & 1.000 & 1.000 & 1.000 & 1.000 & 1.000 & 1.000 \\
\hline Mean & 0.883 & 0.883 & 0.874 & 0.874 & 0.831 & 0.848 & 0.869 \\
\hline
\end{tabular}

The DEA results were estimated via DEAP 2.1/Octave software. The results indicate that there is a relative efficiency in the performance of 13 healthcare systems according to the $1^{\text {st }}$ and $2^{\text {nd }}$ scenario in facing Covid-19. Also, there is a relative efficiency in the performance of 11 healthcare systems according to the $3^{\text {rd }}, 4^{\text {th }}$, and $7^{\text {th }}$ scenarios. Besides, the results of the 
$5^{\text {th }}$ and $6^{\text {th }}$ scenarios indicated a relative efficiency in the performance of 7 and 8 healthcare systems, respectively. Simultaneously, the highest mean of relative efficiency for the 29 countries under investigation was about $87.1 \%$ according to the first scenario during the study period, while the lowest mean of relative efficiency was about $83.3 \%$ according to the fifth scenario during the study period. Similarly, panel B, based on the DEA input-oriented model, shows that the same countries remain efficient with a slight increment of $1.2 \%$ in the mean efficiency level according to the first scenario and a slight decrease of $0.2 \%$ in the mean efficiency level according to the fifth scenario. Accordingly, the A1 assumption is supported. By implementing Scenario 2 in the DEA model for the same data, it's noticed that there was no difference in the relative efficiency scores from Scenario 1. However, the implementation of Scenario 3 shows that only three healthcare systems' efficiency scores changed. The efficiency level of Bangladesh's healthcare system decreased by $5.6 \%$ (resp. $2.5 \%$ ) via output (resp. input) oriented model, those associated with Mexico decreased by approximately 20.8\% (resp. 21.1\%) via output (resp. input), and finally, those associated with Egypt decreased by 1.6\% regarding the output and input-oriented models. Similarly, the same efficiency levels were obtained in Scenario 4. This shows that the number of death cases does not influence the obtained relative efficiency scores, whereas the number of conducted tests has no significant influence on the relative efficiency scores of the healthcare systems under study. This supports the A2 assumption.

Considering only the number of affected cases versus the number of recovered cases decreases the efficient countries by $46 \%$ (6 countries), as it is shown in Table 2 under the output and input-oriented models. Besides, the mean relative efficiency was approximately $83 \%$ during the study period (Jan-Sep 2020) according to that scenario. Scenario 6 and 7 were used to check the impact of the number of medical practitioners, and hospital beds, as a supportive input, on the relative efficiency scores of the countries under study. There was no significant difference in the sets of efficient units between Scenario 5 and 6. However, adding the number of beds, as input, to Scenario 5, results in shifting the efficiency scores associated with India, Nigeria, Ethiopia, and DR Congo to $100 \%$. This shows that the number of beds has more influence on the efficiency scores than the number of medical practitioners. This also supports the A2 assumption. Following the above analysis, the investigated countries will be classified based on their efficiency scores in adopted Scenarios.

Following the above analysis, the investigated countries will be classified based on their efficiency scores in Scenario 2 , Scenario 3, and Scenario 7. The DEA results, corresponding to the last three scenarios, show that there are four categories, as follows:

- Category 1. Completely efficient: Contains the countries that are efficient in the three scenarios.

- Category 2. nearly efficient: Contains the countries with an average efficiency level of $90 \%$ or above for the three scenarios.

- Category 3. Inefficient: Contains countries with an average efficiency level between $70 \%$ and $90 \%$ for the three scenarios.

- Category 4. Severely Inefficient: Contains the countries that are inefficient in the three scenarios and with efficiency scores less than $70 \%$.

Eleven countries: China, India, Pakistan, Brazil, Nigeria, Ethiopia, Vietnam, DR Congo, Tanzania, South Africa, and Colombia belong to the first category and are efficient in the three scenarios. However, when the inputs involve only the number of affected cases and the number of medical practitioners (as in Scenario 6), India, Nigeria, Ethiopia, and DR Congo show inefficiency that indicates that despite the efficiency of these countries, the medical practitioners were not optimally utilized. Within Category 2, Russia, Japan, Turkey, Iran, Germany, Thailand, and South Korea have efficiency scores strictly between $90 \%$ and $100 \%$ in all the three considered scenarios. It is noticeable that these countries are not optimally using their healthcare systems' resources and they need to improve their performance. It can be noted that fewer resources should be sufficient to get the obtained level of recovered cases. Remarkably, Egypt has efficiency scores above $90 \%$ that jump to $100 \%$ when all the inputs are included, which means that the number of conducted Covid-19 tests is crucial for the performance of the healthcare system of this specific country. Six countries fall into the third category. Four of these countries have consistent scores regardless of the scenario. The United States, Indonesia, and Italy have efficiency scores around $70 \%$, while the Philippines has efficiency scores around $88 \%$, in all three scenarios. This illustrates that none of the inputs under this study influences their performance neither positively nor negatively. For Bangladesh and Mexico, the efficiency scores of their healthcare systems increased to above $90 \%$ for Bangladesh and $100 \%$ for Mexico in Scenario 2 , which indicates that the number of conducted Covid-19 tests has a positive effect on the performance of these countries. The United Kingdom, France, Myanmar, and Kenya belong to the last category. Indeed, the former two countries have efficiency scores less than $33 \%$ in all the scenarios, which reflects a very weak performance, and thus the available resources are not utilized appropriately. Remarkably, Myanmar efficiency scores have a big gap between input and output orientation, the input-oriented scores are almost double those of the output. Analyzing these results leads to the fact that the healthcare resources are not optimally utilized, and it is recommended to decrease the allocated resources by at least $20 \%$ and increase the number of recovered cases simultaneously by at least $40 \%$.

\section{Statistical Analysis}

In this section, statistical tests will be conducted to support the DEA results. Moreover, the following hypotheses will be tested: 
H1. The variance between the healthcare systems' scores obtained from the DEA model based on the various considered scenarios is not statistically significant.

H2. The variance between the healthcare systems' scores based on the orientation of the DEA model is not statistically significant.

H3. All the considered inputs and outputs variables under analyses have no statistically significant impact on the healthcare systems' scores over the study period.

H4. The GDP per capita has no statistically significant influence on the healthcare systems' scores over the study period.

\subsection{DEA-Orientation Differences Tests}

Table 3 displays the results of the Sign test and the Wilcoxon test (using IBM SPSS Ver. 26) to determine whether there is a statistically significant difference in the healthcare systems' efficiency scores between the DEA output and input-oriented models. The results of the sign and the Wilcoxon tests support the null hypothesis that the median of differences between both models is equal to zero according to all considered scenarios except the $5^{\text {th }}$ and $7^{\text {th }}$ scenarios, where there was a significant difference between the efficiency scores according to scenario 5 in favor of the output-oriented model, while there was a significant difference according to scenario 7 in favor of the input-oriented model. Accordingly, the H2 hypothesis is partially supported.

Table 3

Test results of the differences among the DEA models orientation

\begin{tabular}{ccccccccc}
\hline \multirow{2}{*}{ Test } & & \multicolumn{5}{c}{ Test Statistics } \\
\cline { 2 - 7 } & & Scenario 1 & Scenario 2 & Scenario 3 & Scenario 4 & Scenario 5 & Scenario 6 & Scenario 7 \\
\hline Wilcoxon test & Sig. & 0.574 & 0.574 & 0.412 & 0.412 & $0.003 * *$ & 0.628 & $0.038^{*}$ \\
Sign test & Sig. & 0.267 & 0.267 & 0.180 & 0.180 & $0.003^{* *}$ & 0.118 & $0.022^{*}$ \\
\hline
\end{tabular}

Note: * and $* *$ are significant at the 5 and $1 \%$ levels, respectively.

Based on the previous results, the decision-makers can adopt any orientation, whether output orientation or input orientation, when trying to improve the relative efficiency of the performance of the inefficient healthcare systems of countries under investigation, according to all scenarios except for the 5 and 7 scenarios, as there is a preference for the output-oriented model within the $5^{\text {th }}$ scenario and preference for the input-oriented model within the $7^{\text {th }}$ scenario. Accordingly, based on all of the above, the $\mathrm{H} 2$ hypothesis is partially supported.

\subsection{Relative Efficiency drivers}

The existing study uses the Tobit regression analysis to set the drivers of the healthcare systems' efficiency. Table 4 exposes the Tobit analysis to determine the impact of the independent variables: the total number of recovered cases, reverse ratio of death cases, total tests, affected cases, medical practitioners, hospital beds, and GDP per capita, on the healthcare systems' efficiency scores (dependent variable) over the study period.

Table 4

The results of the Tobit regression

\begin{tabular}{|c|c|c|c|c|c|c|c|c|}
\hline \multirow{2}{*}{ Variables } & \multicolumn{4}{|c|}{ Panel A: Output-orientation model } & \multicolumn{4}{|c|}{ Panel B: Input-orientation model } \\
\hline & Coef. & Std. Err. & $\mathbf{z}$ & $\mathbf{P}>\mathbf{Z}$ & Coef. & Std. Err. & $\mathbf{z}$ & $\mathbf{P}>\mathbf{Z}$ \\
\hline $\begin{array}{l}\text { Total recovered Cases } \\
\text { (per million) }\end{array}$ & 0.0001601 & 0.0000402 & 3.98 & $0.001^{*}$ & 0.0001543 & 0.0000262 & 5.90 & $0.000^{*}$ \\
\hline $\begin{array}{c}\text { The reverse ratio of } \\
\text { total deaths }\end{array}$ & 0.161422 & 0.1124614 & 1.44 & 0.165 & 0.1276241 & 0.0830522 & 1.54 & 0.139 \\
\hline $\begin{array}{l}\text { Total Tests } \\
\text { (per million) }\end{array}$ & -0.0000006 & 0.0000007 & -0.98 & 0.337 & -0.0000007 & 0.0000004 & -1.56 & 0.133 \\
\hline $\begin{array}{l}\text { Total affected Cases } \\
\text { (per million) }\end{array}$ & -0.0000981 & 0.0000327 & -3.00 & $0.007^{*}$ & -0.0000976 & 0.0000211 & -4.63 & $0.000^{*}$ \\
\hline $\begin{array}{c}\text { Total medical practitioners } \\
\text { (per million) }\end{array}$ & -0.0000098 & 0.0000347 & -0.28 & 0.781 & -0.0000076 & 0.0000226 & -0.34 & 0.739 \\
\hline $\begin{array}{l}\text { Total hospital beds } \\
\quad \text { (per million) }\end{array}$ & 0.0000089 & 0.0000275 & 0.32 & 0.749 & 0.0000068 & 0.0000179 & 0.38 & 0.709 \\
\hline $\begin{array}{c}\text { Total GDP } \\
\text { (per capita \$) }\end{array}$ & 0.0000016 & 0.0000067 & 0.24 & 0.810 & 0.0000013 & 0.0000043 & 0.31 & 0.760 \\
\hline Constant & 0.9111007 & 0.0767776 & 11.87 & $0.000^{*}$ & 0.9226001 & 0.0497668 & 18.54 & $0.000^{*}$ \\
\hline Pseudo R2 & 0.8278 & & & & 1.3257 & & & \\
\hline$\chi^{2}$ & 24.34 & & & $0.001^{*}$ & 34.73 & & & $0.000^{*}$ \\
\hline $\mathbf{N}$ & 29 & & & & 29 & & & \\
\hline
\end{tabular}

Notes: * is significant at the $1 \%$ level.

Table 4 summarizes the efficiency drivers of these healthcare systems according to the first scenario of the DEA output and input-oriented models, respectively, using the Tobit analysis. The overall scores of these healthcare systems' efficiencies are positively associated with the total number of recovered cases per million at the 0.01 significance level. This means that 
the countries will be more relatively efficient if they can increase the total cases recovering from the COVID-19 pandemic. On the other side, the total number of affected cases per million has a significant negative impact on the efficiency scores at the 0.01 significance level. This means that the countries will be more relatively efficient if they can decrease the total affected cases from the COVID-19 pandemic. The decision makers can achieve these above targets by taking and implementing some decisions such as instructing citizens about precautionary actions, full or partial lockdown, improving the efficiency of healthcare systems' workers, providing the necessary supplies, etc. Simultaneously, the other variables have insignificant effects on the overall scores of efficiencies. It is shown that the reverse ratio of death cases and hospital beds has an insignificant positive impact on the efficiency scores, while the total tests and medical practitioners have an insignificant negative impact on the efficiency scores. According to all of the above, the H3 is partially supported. Besides, the GDP per capita has an insignificant positive influence on the efficiency scores. Accordingly, the H4 hypothesis is supported.

\subsection{Findings Validity Test}

A validity test was adopted to verify the cogency of the findings. Indeed, this test is done by changing the input(s) and output(s) combinations, then checking the influence on the DEA scores using various statistical tests. Table 5 shows the results when each variable is excluded sequentially from the basic DEA model scenario (Alrashidi, 2015; Fixler et al., 2014; Habib and Shahwan, 2020). The Spearman rank test was also applied to verify the correlation between the main DEA model (scenario 1) and the modified models (rest of scenarios). Besides, The Mann-Whitney U test was employed to verify if the two distributions' shapes (main scenario and each modified scenario) are identical. Also, to enhance the results of the internal robustness test of the basic model, the Kruskal-Wallis H test was utilized to verify whether there is a significant difference between the efficiency scores acquired from the various considered scenarios.

Table 5

Validity test of the DEA models results

\begin{tabular}{|c|c|c|c|c|c|}
\hline $\begin{array}{c}\text { Panel A: Output-orientation model } \\
\text { Scenarios }\end{array}$ & $\begin{array}{c}\text { Average Efficiency } \\
\text { Score }\end{array}$ & $\begin{array}{c}\text { Efficient } \\
\text { DMUs (\%) }\end{array}$ & $\begin{array}{l}\text { Spearman Rank } \\
\text { Correlation Sig. }\end{array}$ & $\begin{array}{c}\text { Mann } \\
\text { Whitney U Sig. }\end{array}$ & $\begin{array}{c}\text { Kruskal Wallis } \\
\text { H Sig. }\end{array}$ \\
\hline Scenario 1 (Basic model) & 0.871 & 45 & -- & -- & \multirow{7}{*}{0.782} \\
\hline Scenario 2 & 0.870 & 45 & $1.000^{*}$ & 0.993 & \\
\hline Scenario 3 & 0.861 & 38 & $0.914^{*}$ & 0.663 & \\
\hline Scenario 4 & 0.861 & 38 & $0.914 *$ & 0.657 & \\
\hline Scenario 5 & 0.833 & 24 & $0.744^{*}$ & 0.195 & \\
\hline Scenario 6 & 0.835 & 28 & $0.746^{*}$ & 0.235 & \\
\hline Scenario 7 & 0.859 & 38 & $0.914^{*}$ & 0.651 & \\
\hline \multicolumn{6}{|l|}{ Panel B: Input-orientation model } \\
\hline Scenarios & $\begin{array}{c}\text { Average Efficiency } \\
\text { Score }\end{array}$ & $\begin{array}{c}\text { Efficient } \\
\text { DMUs (\%) }\end{array}$ & $\begin{array}{l}\text { Spearman Rank } \\
\text { Correlation Sig. }\end{array}$ & $\begin{array}{l}\text { Mann-Whitney U } \\
\text { Sig. }\end{array}$ & $\begin{array}{c}\text { Kruskal-Wallis } \\
\text { H Sig. }\end{array}$ \\
\hline Scenario 1 (Basic model) & 0.883 & 45 & -- & -- & \multirow{7}{*}{0.711} \\
\hline Scenario 2 & 0.883 & 45 & $1.000^{*}$ & 1.000 & \\
\hline Scenario 3 & 0.874 & 38 & $0.911^{*}$ & 0.640 & \\
\hline Scenario 4 & 0.874 & 38 & $0.911^{*}$ & 0.640 & \\
\hline Scenario 5 & 0.831 & 24 & $0.726^{*}$ & 0.155 & \\
\hline Scenario 6 & 0.848 & 28 & $0.766^{*}$ & 0.220 & \\
\hline Scenario 7 & 0.869 & 38 & $0.901 *$ & 0.600 & \\
\hline $\begin{array}{r}\text { Panel C: Output-orientation model } \\
\text { Spearman Rank } \\
\text { Asymp. Sig. (M }\end{array}$ & $\begin{array}{l}\text { lvs Input-oriented mo } \\
\text { k Correlation Sig. } \\
\text { Mann-Whitney U) }\end{array}$ & (Basic model) & $\begin{array}{c}0.933^{*} \\
0.967 \\
\end{array}$ & & \\
\hline
\end{tabular}

Notes: $*$ is significant at the $1 \%$ level.

It is shown in Table 5, that the average efficiency scores for all scenarios under each orientation model are compromised between $83 \%$ and $89 \%$. The average of the efficiency scores according to the main model (scenario 1 ) is $87.1 \%$ (resp. $88.3 \%$ ) via output (resp. input) orientation, which is the highest average efficiency score compared to the rest of the scenarios within the same orientation. Besides, the main scenario showed the highest number of efficient countries (DMUs), where approximately $45 \%$ of the healthcare systems under study are efficient. However, the $5^{\text {th }}$ scenario showed the lowest average efficiency scores with an average of $83 \%$ and $24 \%$ efficient countries in both orientations. Moreover, it can be observed in Table 5 that the Spearman rank test under each orientation model refers to a high correlation between the basic model and the modified models. Simultaneously, the Mann-Whitney U test supports the null-hypothesis, which claims that the distributions of the efficiency scores for the basic model have the same shape as distributions of the efficiency scores for each modified model. Besides, the Kruskal-Wallis $\mathrm{H}$ test supports the null-hypothesis, stating that the distribution shapes of all models have the same shape, thus indicating the internal validity and robustness of the basic DEA model, and the H1 hypothesis is supported.

Also, in panel C, the Spearman rank test shows a high correlation between the efficiency scores of the basic DEA model according to the output and input orientation. Simultaneously, the Mann-Whitney U test shows that the distributions of the efficiency scores for the basic model according to the output and input orientation have the same shape, thus also indicating the internal validity and robustness of the basic DEA models. 


\section{Conclusion}

The current study assessed the performance of 29 healthcare systems' of countries that have above fifty million citizens in facing the Covid-19 virus using the DEA methodology during the period of Jan-Sep 2020. The study adopted multi scenarios according to the DEA models' orientation to provide multiple choices, which can be more helpful in continuous improvement activities, to decision makers in countries to achieve the best practice like the completely efficient countries. The DEA models under both orientations showed close results of the average efficiency scores according to all scenarios. The main model (Scenario 1) under both output and input orientations recorded the highest average scores by approximately $87.1 \%$ and $88.3 \%$, respectively, with $45 \%$ efficient countries.

The results of the sign test and the Wilcoxon test for DEA orientations scenarios refer that the decision-makers can depend on any orientation to achieve the best practices except for the $5^{\text {th }}$ and $7^{\text {th }}$ scenarios, where the preference was for the output and input-oriented models, respectively. Besides, The DEA results referred to the countries that have inefficient performance, where changes or optimizations are required to reach complete efficiency and achieve best practices, like the efficient ones.

The Tobit analysis indicates that the countries will be more efficient if they can increase the total recovered cases and decrease the total affected cases from the COVID-19 pandemic. Countries can achieve these targets by taking efficient actions like precautionary actions, instructing citizens, full or partial lockdown, supporting healthcare workers, providing necessary supplies, etc.

Overall, the findings of the current study raise important implications, in which the findings assert the importance of continuous improvement of performance to achieve the best practices regarding relative efficiency, the linkage between the healthcare systems' resources, and the needed outputs. In the context of the COVID-19 pandemic, the study sheds light on the relative efficiency drivers, which, by employing them well, the decision-makers can reach the maximum relative efficiency. The current study also provides acceptable scenarios of DEA models that can be useful in benchmarking the countries' efficiencies in facing the Covid-19 pandemic. Besides, the use of the adopted scenarios via the DEA models and the Tobit analysis model provides countries' decision makers with fresh tools for assessing the performance level of healthcare systems and identifying the major drivers of the overall performance.

Accordingly, future researches, using the DEA approach and the relevant statistical analysis tools, are recommended to assess the healthcare systems of various countries regarding the second wave of the spread of the COVID-19 pandemic and make comparisons with the findings regarding the first wave of the pandemic, which can be helpful to verify the extent of improvement in the relative efficiency of countries in facing the COVID-19 pandemic.

\section{References}

Alexander, C. A., Busch, G., \& Stringer, K. (2003). Implementing and interpreting a data envelopment analysis model to assess the efficiency of health systems in developing countries. IMA Journal of Management Mathematics, 14(1), 4963.

Alrashidi, A.N. (2015). Data envelopment analysis for measuring the efficiency of head trauma care in England and Wales. Ph.D. thesis, Salford Business School, University of Salford, Manchester, The United Kingdom.

Banker, R., Charnes, A., \& Cooper, W.W. (1984). Some models for estimating technical and scale inefficiencies in data envelopment analysis. Management Science, 30(9), 1078-1092.

Banker, R.D., Charnes, A., Cooper, W.W., Swarts, W., \& Thomas, D. (1989). An introduction to data envelopment analysis with some of its models and their uses. Research in Governmental and Nonprofit Accounting, 5(1), 125-163.

Charnes, A., Cooper, W.W., \& Rhodes, E. (1978). Measuring the efficiency of decision-making units. European Journal of Operational Research, 2(6), 429-444.

Chen, Z., Ming, X., Wang, R., \& Bao, Y. (2020). Selection of design alternatives for the smart product-service system: A rough-fuzzy data envelopment analysis approach. Journal of Cleaner Production, 273, 122931.

Cooper, W.W., Seiford, L.M., \& Tone, K., (2007). Data envelopment analysis: a comprehensive text with models, applications, references and DEA-solver software. $2^{\text {nd }}$ ed., Springer, New York.

Coronatracker Homepage, https://www.coronatracker.com (last accessed Oct. 1, 2020).

Emrouznejad, A., \& Yang, G.L. (2018). A survey and analysis of the first 40 years of scholarly literature in DEA: 19782016. Socio-Economic Planning Sciences, 61(1), 4-8.

Fixler, T., Paradi, J.C., \& Yang, X. (2014). A data envelopment analysis approach for measuring the efficiency of Canadian acute care hospitals. Health Services Management Research, 27(3-4), 57-69.

Golany, B.A., \& Roll, Y., (1989). An application procedure for data envelopment analysis. Omega, 17(3), $237-250$.

Habib, A.M., \& Shahwan, T.M. (2020). Measuring the operational and financial efficiency using a Malmquist data envelopment analysis: a case of Egyptian hospitals. Benchmarking: An International Journal, 27(9), 2521-2536.

Hatami-Marbini, A., Emrouznejad, A., \& Tavana, M. (2011). A taxonomy and review of the fuzzy data envelopment analysis literature: two decades in the making. European Journal of Operational Research, 214(3), 457-472. 
Ibrahim, M. D., Daneshvar, S., Hocaoğlu, M. B., \& Oluseye, O. W. G. (2019). An Estimation of the Efficiency and Productivity of Healthcare Systems in Sub-Saharan Africa: Health-Centred Millennium Development Goal-Based Evidence. Social Indicators Research, 143(1), 371-389.

Index Mundi Homepage, https://www.indexmundi.com (last accessed Sep. 13, 2020).

International Monetary Fund Homepage, https://www.imf.org/external/index.htm (last accessed Oct. 6, 2020).

Kohl, S., Schoenfelder, J., Fugener, A., \& Brunner, J.O. (2019). The use of Data Envelopment Analysis (DEA) in healthcare with a focus on hospitals. Health Care Management Science, 22(2), 245-286.

Koltai, T., \& Uzonyi-Kecskes, J. (2017). The Comparison of Data Envelopment Analysis (DEA) and Financial Analysis Results in a Production Simulation Game. Acta Polytechnica Hungarica: Journal of Applied Science, 14(4), $167-185$.

Lo Storto, C. (2013). Evaluating Technical Efficiency of Italian Major Municipalities: A Data Envelopment Analysis model. Procedia - Social and Behavioral Sciences, 81, 346-350.

Masiye, F. (2007). Investigating health system performance: an application of data envelopment analysis to Zambian hospitals. BMC Health Services Research, 7(58), 1-11.

Mourad, N., \& Tharwat, A. (2019). Mixed Stochastic Input Oriented Data Envelopment Analysis Model. International Journal of Scientific \& Technology Research, 8(12), 1839-1845.

Mourad, N., \& Tharwat, A. (2020). The Efficiency of a University’s Colleges: A Case Study using Data Envelopment Analysis. Journal of Advanced Research in Dynamical and Control Systems, 12(8), 515-523.

Olesen, O. B., \& Petersen, N. C. (2016). Stochastic data envelopment analysis-A review. European Journal of Operational Research, 251(1), 2-21.

Sexton, T. R. (1986). The methodology of data envelopment analysis. New directions for program evaluation, $32,7-29$.

Shahwan, T.M., \& Habib, A.M. (2020). Does the efficiency of corporate governance and intellectual capital affect a firm's financial distress? Evidence from Egypt. Journal of Intellectual Capital, 21(3), 403-430.

Tone, K. (2016). Data Envelopment Analysis as a Kaizen Tool: SBM Variations Revisited. Bulletin of Mathematical Sciences and Applications, 16, 49-61.

Unger, J. P., \& De Paepe, P. (2019). Commercial health care financing: the cause of US, Dutch, and Swiss health systems inefficiency?. International Journal of Health Services, 49(3), 431-456.

Verbeek, M. (2008). A guide to modern econometrics. John Wiley \& Sons.

Wang, x., Luo, H., Qin, X., Feng, J., Gao, H., \& Feng, Q. (2016). Evaluation of performance and impacts of maternal and child health hospital services using Data Envelopment Analysis in Guangxi Zhuang Autonomous Region, China: a comparison study among poverty and nonpoverty county-level hospitals. International Journal for Equity in Health, 15(131), 1-6.

World Health Organization Homepage, https://www.who.int (last accessed Oct. 1, 2020).

Worldometers Homepage, https://www.worldometers.info (last accessed Oct. 1, 2020).

Zakowska, I., \& Godycki-Cwirko, M. (2020). Data envelopment analysis applications in primary health care: a systematic review. Family Practice, 37(2), 147-153.

Zheng, W., Sun, H., Zhang, P., Zhou, G., Jin, Q., \& Lu, X. (2018). A four-stage DEA-based efficiency evaluation of public hospitals in China after the implementation of new medical reforms. Public Library of Science (PLOS), 13(10), 1-17.

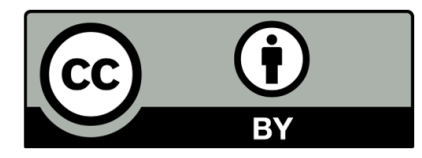

(C) 2021 by the authors; licensee Growing Science, Canada. This is an open access article distributed under the terms and conditions of the Creative Commons Attribution (CC-BY) license (http://creativecommons.org/licenses/by/4.0/). 